\title{
Effects of the Reaction Parameters and Light Hydrothermal Aging for Catalytic Combustion of Propane over Co-Mn-Ce Catalyst
}

\author{
Lili Lei $\mathbb{D}$, Miaomiao Jin, Chenrui Cui, Kai Li, and Pan Wang \\ School of Automotive and Traffic Engineering, Jiangsu University, Zhenjiang 212013, China \\ Correspondence should be addressed to Lili Lei; 1110817@ujs.edu.cn
}

Received 10 September 2021; Accepted 17 January 2022; Published 10 February 2022

Academic Editor: Ajaya Kumar Singh

Copyright ( $) 2022$ Lili Lei et al. This is an open access article distributed under the Creative Commons Attribution License, which permits unrestricted use, distribution, and reproduction in any medium, provided the original work is properly cited.

\begin{abstract}
A composite oxides' Co-Mn-Ce catalyst was synthesized by a coprecipitation method, and the experiment was carried out to study the effects of reaction parameters and light hydrothermal aging on propane combustion over the Co-Mn-Ce catalyst. The influence of reaction temperature, propane concentration, oxygen concentration, water vapor, and hydrothermal aging was studied during the catalytic combustion of propane. The propane conversion significantly decreased by $10 \%$ when the propane concentration increased at $300^{\circ} \mathrm{C}$ and then further decreased from $80 \%$ to $40 \%$ as water vapor concentration increased from 0 to 10 vol.\%. In addition, water vapor also prolonged the time required to reach equilibrium. After hydrothermal treatment, the catalyst obtained the lowest oxidation capacity of propane. Furthermore, the results of in situ DRIFTs and $\mathrm{O}_{2}$ temperature programmed desorption $\left(\mathrm{O}_{2}\right.$-TPD) demonstrated that there were fewer oxygen species after hydrothermal aging, and carbonates were the main intermediates formed during the catalytic oxidation of propane.
\end{abstract}

\section{Introduction}

Volatile organic compounds (VOCs) are atmospheric pollutants emitted from a wide range of industrial processes and motor vehicle fuel combustion and cause chemical smog, haze, and ozone generation [1-3]. Propane emission is a light alkane VOC that is mainly produced from petrochemical processes and engines that use fossil fuels. Catalytic oxidation is considered an effective method for VOCs degradation due to its low operating temperature range $\left(300-600^{\circ} \mathrm{C}\right)$ and because it does not require additional fuel and produces less secondary pollution than thermal oxidation $[4,5]$. The catalytic oxidation of propane commonly requires large amounts of energy and active oxygen species during the reaction. It remains challenging to develop catalysts that demonstrate high performance at low temperatures.

Generally, the catalysts used for the total oxidation of propane include noble metals, transition metal oxides, and molecular sieves [6-8]. Transition metal oxides are thermally stable, nontoxic, and inexpensive [9-11], which have been investigated as substitutes for precious metal catalysts $[12,13]$. Among transition metals, mixed oxides show synergistic effects that produce catalytic activities than single-metal oxides. Zhao et al. [14] added $\mathrm{Mn}$ to $\mathrm{Co}_{3} \mathrm{O}_{4}$ to form a solid solution with spinel structure, which can significantly improve the catalytic activity of pure $\mathrm{Co}_{3} \mathrm{O}_{4}$, and can completely oxidize toluene and ethyl acetate at 220 and $180^{\circ} \mathrm{C}$. Tang et al. [15] reported that Mn-Co mixed oxide nanorod with porous structure and high surface area formed solid solution with spinel structure, which inhibited the growth of nanoparticles that leaded to its higher surface area. While, a strong synergistic effect of Mn-Co species in the oxide made a great contribution to its low-temperature reducibility which played a key role in VOCs oxidation. Castano et al. [16] discovered that the redox properties and the oxygen mobility played a determining role in the oxidation of the VOCs, with the oxygen mobility playing a more significant role in the cobalt oxides, whereas the redox properties were fundamental in the manganese oxides and in 
the Co and Mn mixture. Tang et al. [17] revealed that the hierarchical layer-stacking Mn-Ce composite oxide possessed superior physiochemical properties such as good lowtemperature reducibility, high manganese oxidation state, and rich adsorbed surface oxygen species which resulted in the enhancement of catalytic abilities. Geng et al. [18] found that Ce can maintain the structure of the catalyst and prevent $\mathrm{Mn}^{4+}$ and $\mathrm{Mn}^{3+}$ from reducing to $\mathrm{Mn}^{2+}$, which had good stability. Meanwhile, Tian et al. [19] found out that with the substitution of cobalt cations with $\mathrm{Mn}^{3+}$ and $\mathrm{Mn}^{4+}$ ions, the ratio $\mathrm{Co}^{3+} / \mathrm{Co}^{2+}$ decreased and both electrical resistivity and thermal stability showed increasing trends, which attributed to the progressive incorporation of manganese induced structural defects favoring the formation of anionic vacancies and the restriction of the oxygen mobility. Feng et al. [20] prepared $\mathrm{Cu}-\mathrm{Mn}$-Ce catalyst and found that unpaired electrons on the catalyst surface and $\mathrm{Mn}$ replacement in the catalyst crystal played an important role in the catalytic process, and the three metal oxides had a strong synergistic effect to significantly improve the catalytic activity. Deng et al. [21] found out that a solid solution was formed with more active oxygen induced by Co doping, while strong interaction effects among Co-Mn-Ce-O were speculated as the main mechanisms underlying the high efficiency catalytic capacity. Gómez et al. [22] found that $\mathrm{Co}_{3} \mathrm{O}_{4} / \mathrm{La}-\mathrm{CeO}_{2}$ contained more lattice oxygen species caused by $\mathrm{Co}^{3+} / \mathrm{Co}^{2+}$ and $\mathrm{Ce}^{4+} / \mathrm{Ce}^{3+}$ couples, which contributed to increased performance for toluene degradation. Kan et al. [23] reported that $\mathrm{Mn}_{8} \mathrm{Co}_{1} \mathrm{Ce}_{1} /$ cordierite presented the best activity and stability among all of the catalysts synthesized. The results were attributed to the synergistic effect of ceria, manganese, and cobalt, which could promote the formation of more lattice defects, more oxygen vacancies, and smaller crystallite sizes.

The influence of water vapor on adsorption, catalytic oxidation, and the deposition of coke during the catalytic combustion of VOCs was also studied to understand the catalytic oxidation mechanism $[24,25]$. In the presence of water vapor, the adsorption sites occupied by water vapor resulted in inaccessible of VOCs to adsorption sites [26, 27], the competitive adsorption of water vapor. In addition, some researchers found that the catalytic oxidation performance could also be affected by catalyst deactivation and operating temperature [28-30]. Bae et al. [31] showed that Mn-doped $\mathrm{CuOeCo}_{3} \mathrm{O}_{4} \mathrm{eCeO}_{2}$ catalyst significantly enhanced activity and durability due to better preserved $\mathrm{Co}_{3} \mathrm{O}_{4}$ phase.

Although some progress has been made using Co-Mn$\mathrm{Ce}$ composite catalysts for the catalytic combustion of VOCs, there are still few reports about the effect of reaction temperature, water vapor, and reaction conditions on the catalytic activity of VOCs. In this work, a Co-Mn-Ce catalyst was synthesized via a simple coprecipitation method and then used in the catalytic combustion of propane. The factors influencing oxidation performances including reaction temperature, $\mathrm{C}_{3} \mathrm{H}_{8}$ and $\mathrm{O}_{2}$ concentration, and hydrothermal aging were investigated. The chemical properties of the catalysts were characterized by $\mathrm{O}_{2}$-TPD and in situ DRIFTs. In addition, the chemical reaction mechanism of Co-Mn-Ce catalytic oxidation of propane was evaluated.

\section{Materials and Methods}

2.1. Catalyst Preparation. The composite oxides' Co-Mn-Ce catalyst (Co:Mn:Ce=3:1:2, molar ratio) was prepared using a coprecipitation method. $\mathrm{Co}\left(\mathrm{NO}_{3}\right)_{2} \cdot 6 \mathrm{H}_{2} \mathrm{O}$, $\mathrm{Mn}\left(\mathrm{CH}_{3} \mathrm{COOH}\right)_{2} \cdot 4 \mathrm{H}_{2} \mathrm{O}$, and $\mathrm{Ce}\left(\mathrm{NO}_{3}\right)_{3} \cdot 6 \mathrm{H}_{2} \mathrm{O}$ were dissolved in water, while the $\mathrm{pH}$ value was kept around 9.0. After stirring at room temperature for $1 \mathrm{~h}$, the as-obtained homogeneous solution was filtered, washed, dried overnight at $110{ }^{\circ} \mathrm{C}$, and calcined at $500^{\circ} \mathrm{C}$ for $4 \mathrm{~h}$ to acquire the Co$\mathrm{Mn}-\mathrm{Ce}$ catalyst. The sample was labelled as CMC. In addition, the fresh CMC catalyst was light hydrothermally aged in $\left(10 \% \mathrm{H}_{2} \mathrm{O}+10 \% \mathrm{O}_{2}\right) / \mathrm{N}_{2}$ at $750^{\circ} \mathrm{C}$ for $4 \mathrm{~h}$ and labelled as CMC-HA.

2.2. Catalyst Characterization. Oxygen temperature programmed desorption $\left(\mathrm{O}_{2}\right.$-TPD) analysis was carried out using a Micromeritics AutoChem (USA) with a thermal conductivity detector (TCD). Approximately $30 \mathrm{mg}$ of samples were pretreated in $\mathrm{He}$ with a flow rate of $30 \mathrm{~mL} / \mathrm{min}$ at $400^{\circ} \mathrm{C}$ for $1 \mathrm{~h}$. When the catalyst cooled to $50^{\circ} \mathrm{C}, \mathrm{O}_{2}$ was introduced until adsorption saturation. Afterward, the catalyst was purged by $\mathrm{He}$ to remove residual oxygen. Finally, $\mathrm{O}_{2}$-TPD was performed by increasing the temperature from 50 to $700^{\circ} \mathrm{C}$ at a heating rate of $10{ }^{\circ} \mathrm{C} / \mathrm{min}$ under $\mathrm{He}$ flow.

In situ DRIFTs spectra were recorded using a Nicolet 6700 FT-IR spectrometer in the spectral range of $400-4000 \mathrm{~cm}^{-1}$. Before the reaction gas was introduced, samples were pretreated at $450^{\circ} \mathrm{C}$ under $\mathrm{N}_{2}$ flow for $1 \mathrm{~h}$. The background spectra were then collected in flowing $\mathrm{N}_{2}$. Subsequently, the catalysts were exposed to a $\mathrm{C}_{3} \mathrm{H}_{8} / \mathrm{O}_{2} / \mathrm{N}_{2}$ gas mixture to investigate their activity during catalytic combustion of propane.

2.3. Catalyst Performance. Catalytic performance was evaluated in a continuous quartz tubular fixed bed flow reactor $(\varphi 8 \mathrm{~mm} \times 10 \mathrm{~mm})$ as shown in Figure 1 . For each experiment, catalyst powdered (40-60 mesh) was placed in the middle of the flow reactor with the aid of glass fiber. The reaction temperature was measured by a thermocouple, in direct contact with the catalyst bed. The water content was controlled by a precision injection pump, and the heating belt was wrapped in tubular quartz to maintain a temperature over $100 \mathrm{C}$ to prevent water vapor condensation. The data of reactant and products were collected at each temperature by infrared and electrochemical gas analyzers.

Due to the large amounts of water vapor in the exhaust, experiments were evaluated under different water vapor concentrations $(0,5$, and $10 \mathrm{vol} \%)$. The feed was composed of $1000 \times 10^{-6} \mathrm{v} / \mathrm{v}$ propane, $10 \% \mathrm{O}_{2}$, and balance $\mathrm{N}_{2}$, and the reaction was carried out from 100 to $500^{\circ} \mathrm{C}$. The propane concentration was varied $\left(250 \times 10^{-6} \mathrm{v} / \mathrm{v}, 500 \times 10^{-6} \mathrm{v} / \mathrm{v}\right.$, $750 \times 10^{-6} \mathrm{v} / \mathrm{v}$, and $1000 \times 10^{-6} \mathrm{v} / \mathrm{v}$ ) to evaluate its impact at $300^{\circ} \mathrm{C}$. To reflect the effect of hydrothermal aging treatment, the reaction was carried out in a $0 \mathrm{vol} \%$ water vapor atmosphere, at reaction temperatures from $100^{\circ} \mathrm{C}$ to $500^{\circ} \mathrm{C}$. The total gas flow rate was $240 \mathrm{~mL} / \mathrm{min}$ at a space velocity of $48,000 \mathrm{~h}^{-1}$. 


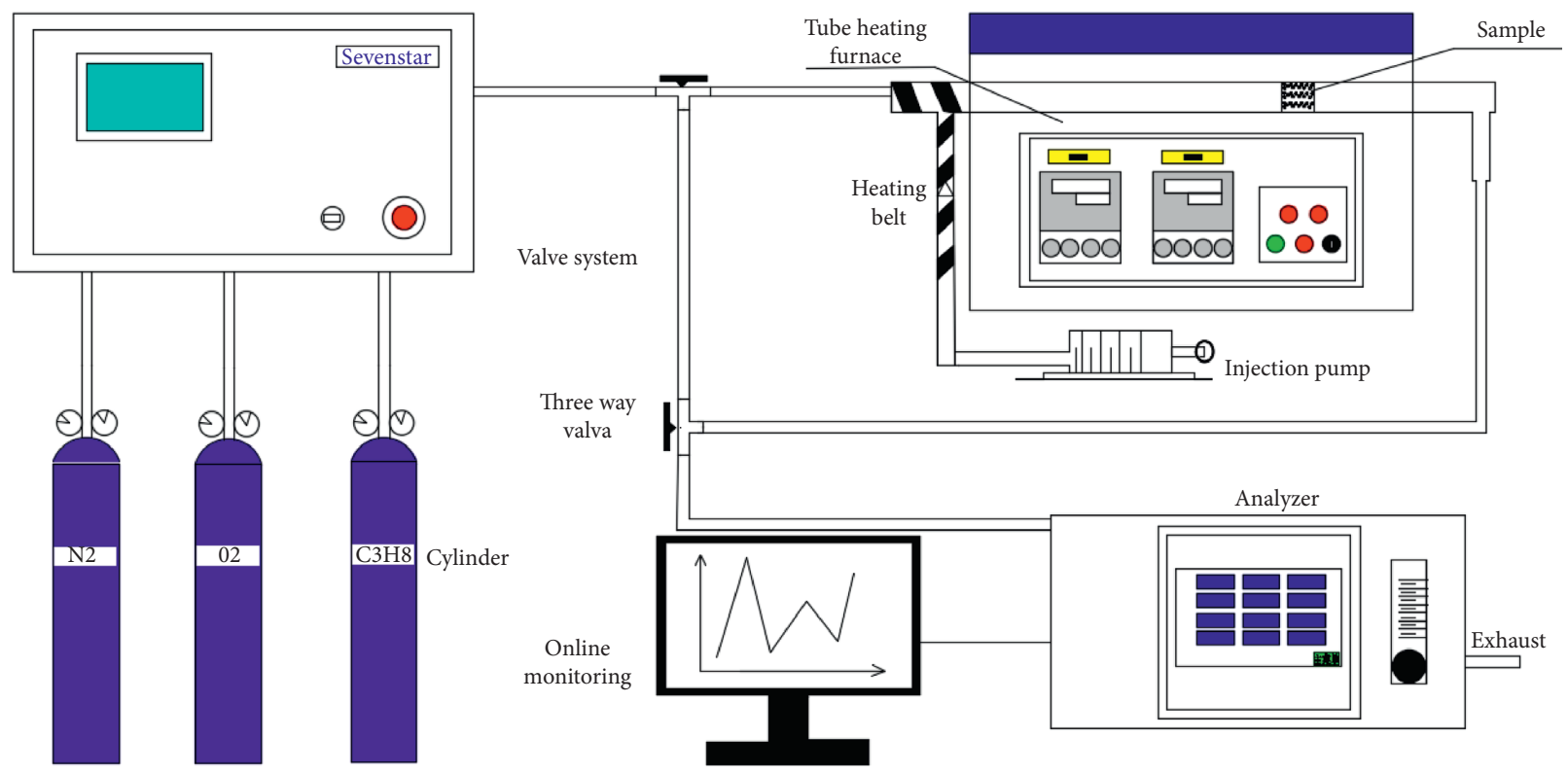

FIgURE 1: Schematic of the catalyst flow reactor experimental system.

Catalytic activities of the CMC catalyst were studied at temperatures from $100^{\circ} \mathrm{C}$ to $500^{\circ} \mathrm{C}$ for acquiring propane conversion of 10,80 , and $90 \%$, respectively $\left(T_{10}, T_{80}\right.$, and $\left.T_{90}\right)$. The propane conversion capacity $\left(\eta_{\text {prpane }} \%\right)$ during the catalytic oxidation of propane was evaluated by the following equation.

$$
\eta_{\text {prpane }} \%=\frac{\left(C_{3} H_{8}\right)_{\text {in }}-\left(C_{3} H_{8}\right)_{\text {out }}}{\left(C_{3} H_{8}\right)_{\text {in }}} \times 100,
$$

where $\left(C_{3} H_{8}\right)_{\text {in }}(v / v)$ and $\left(C_{3} H_{8}\right)_{\text {out }}(v / v)$ represent the concentrations of propane in the inlet gas and the outlet gas, respectively.

\section{Results and Discussion}

\subsection{Reaction Testing}

3.1.1. Effect of Reaction Temperature. The reaction temperature was investigated to understand the propane oxidation process under different water vapor conditions as shown in Figure 2. A significant decrease in propane concentration from $1000 \times 10^{-6} \mathrm{v} / \mathrm{v}$ to $150 \times 10^{-6} \mathrm{v} / \mathrm{v}$ occurred within $30 \mathrm{~s}$ (Figure 2(a) and Figure 2(b)), due to hysteresis during gas switching. Furthermore, the propane concentration increased from 200 to $300^{\circ} \mathrm{C}$, and the increase at $200^{\circ} \mathrm{C}$ was the fastest. The rising rate of propane concentration gradually decreased with increasing temperature. At each temperature, the rate was tending towards stability after $1000 \mathrm{~s}$. This resulted from increasing the temperature, provided more energy for the catalytic oxidation of propane. Notably, the outlet propane concentration reached $900 \times 10^{-6} \mathrm{v} / \mathrm{v}$ without water at $200^{\circ} \mathrm{C}$, and this temperature corresponded to a propane conversion of $10 \%$, which indicated that CMC presented a good low-temperature catalytic activity. The propane concentration was $30 \times 10^{-6} \mathrm{v} / \mathrm{v}$ at $350^{\circ} \mathrm{C}$, and the propane conversion was $97 \% . T_{10}$ and $T_{90}$ under 5 vol $\%$ water vapor conditions were the same as 0 vol $\%$ water vapor. At 10 vol $\%$ water vapor, $T_{10}$ and $T_{90}$ were approximately 250 and $400^{\circ} \mathrm{C}$ (Figure $2(\mathrm{c})$ ).

As shown in Figure 2(d), the propane concentration did not change with the reaction temperature below $200^{\circ} \mathrm{C}$. The propane conversion was similar at 0 vol $\%$ and 5 vol\% water vapor, indicating that the water did not impact the oxidation activity. At 10 vol\% water vapor, the propane conversion decreased at different temperatures, possibly because $\mathrm{H}_{2} \mathrm{O}$ had adsorbed on the active sites and inhibited oxidation.

3.1.2. Effect of Propane Concentration. The results of the propane oxidation experiments showed that the effect of propane conversion at $300^{\circ} \mathrm{C}$ decreased by approximately $40 \%$ when water vapor was introduced in feed gas. When the temperature was below $300^{\circ} \mathrm{C}$, little propane conversion was observed. When the temperature exceeded $300^{\circ} \mathrm{C}$, propane was almost completely oxidized. Therefore, the constant temperature oxidation experiments were carried at $300^{\circ} \mathrm{C}$ to further investigate the effect of propane concentration and water vapor.

The propane concentration curve and conversion diagrams of the CMC catalyst are shown in Figure 3. From Figures $3(\mathrm{a})-3(\mathrm{c})$, the propane concentration $\left(250 \times 10^{-6}\right.$ $\mathrm{v} / \mathrm{v}, 500 \times 10^{-6} \mathrm{v} / \mathrm{v}, 750 \times 10^{-6} \mathrm{v} / \mathrm{v}$, and $\left.1000 \times 10^{-6} \mathrm{v} / \mathrm{v}\right)$ showed a significant decrease in the first $50 \mathrm{~s}$, which was caused by switching the three-way valve to change the reaction gas path. At 0 vol\% water vapor, the propane concentration at the outlet remained constant after $60 \mathrm{~s}$ $\left(39 \times 10^{-6} \mathrm{v} / \mathrm{v}, 107 \times 10^{-6} \mathrm{v} / \mathrm{v}, 201 \times 10^{-6} \mathrm{v} / \mathrm{v}\right.$, and $267 \times 10^{-6}$ $\mathrm{v} / \mathrm{v})$, indicating a stable catalytic performance. At 5 vol\% water vapor condition, the propane concentration remained unchanged after about $100 \mathrm{~s}$. At 10 vol\% water vapor, the reaction required $200 \mathrm{~s}$ to reach equilibrium at constant propane concentration. This indicated that water vapor inhibited catalytic oxidation reaction, and as the water vapor 


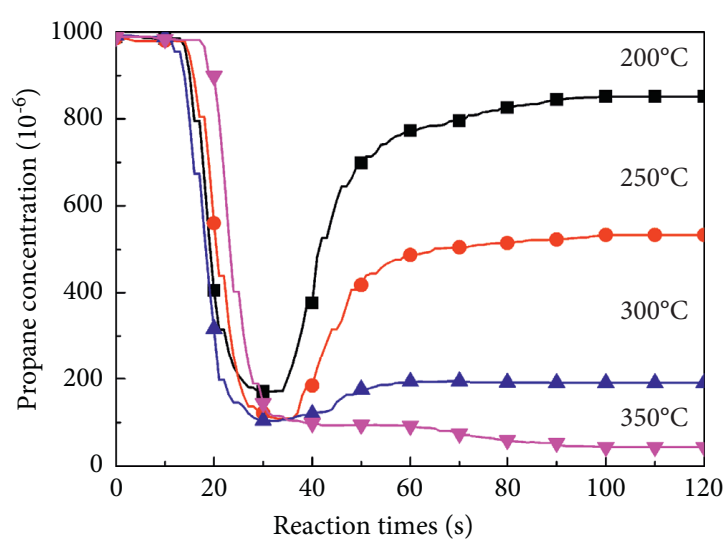

(a)

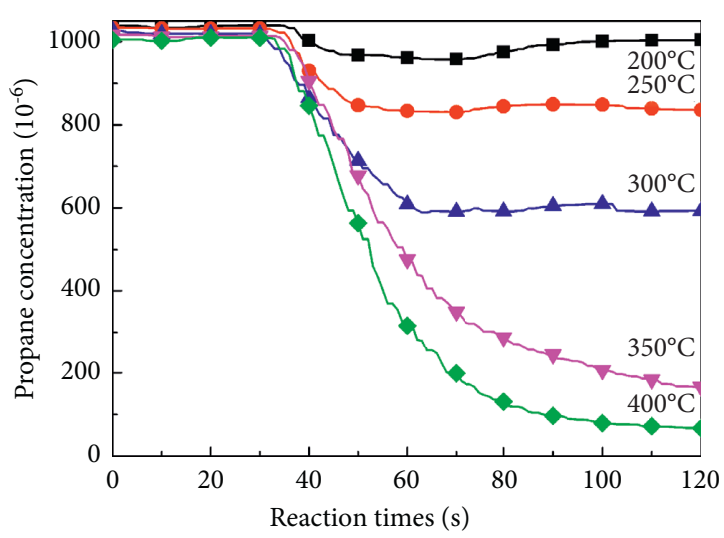

(c)

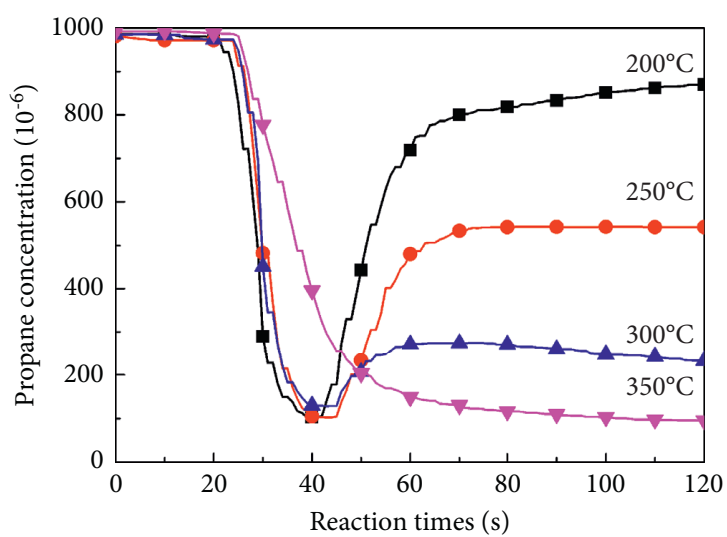

(b)

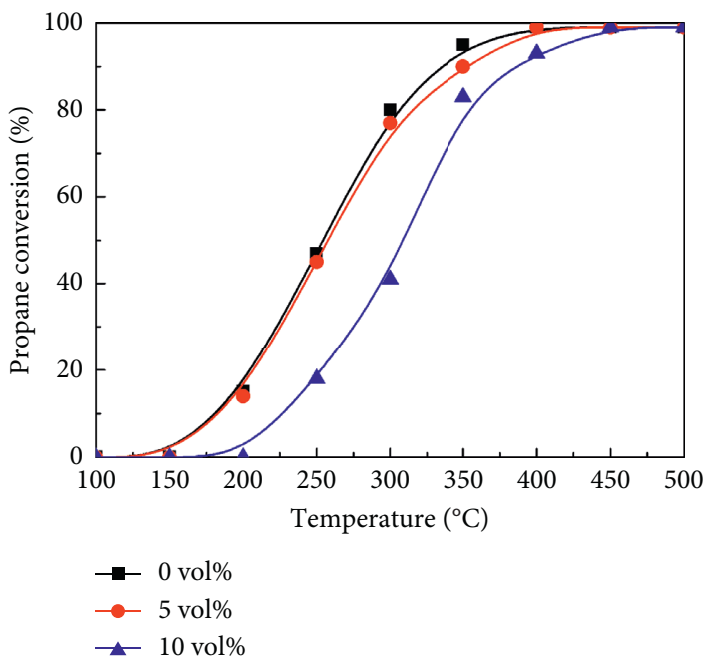

(d)

FiguRe 2: Propane concentration curve and propane conversion curve under different temperatures. (a) 0 vol\% water vapor. (b) 5 vol\% water vapor. (c) 10 vol\% water vapor. (d) Propane conversion.

concentration increased, the reaction took longer to reach equilibrium.

As shown in Figure 3(d), under the same water vapor concentration, the catalytic activity decreased as the propane concentration increased, especially in the absence of water. Notably, at 10 vol\% water vapor, the propane conversion remained nearly unchanged when different propane concentrations were introduced.

3.1.3. Effect of $\mathrm{O}_{2}$ Concentration. The propane concentration curve of the CMC catalyst under various $\mathrm{O}_{2}$ concentrations is shown in Figure 4. At 0 vol\% water vapor, when the $\mathrm{O}_{2}$ concentration was $0 \%$, the concentration of propane at the outlet was $1000 \times 10^{-6} \mathrm{v} / \mathrm{v}$, indicating no oxidation. Upon increasing the $\mathrm{O}_{2}$ concentration from $5 \%$ to $10 \%$, the outlet propane concentration reached $160 \times 10^{-6} \mathrm{v} / \mathrm{v}$, indicating the same propane oxidation. As shown in Figure 4(b), at $5 \mathrm{vol} \%$ water vapor, the outlet propane concentration was $1000 \times 10^{-6} \mathrm{v} / \mathrm{v}$ when the $\mathrm{O}_{2}$ concentration was $0 \%$. Upon introducing $\mathrm{O}_{2}$, the propane concentration at the outlet was stable at $355 \times 10^{-6} \mathrm{v} / \mathrm{v}$. As shown in Figure 4(c), at $10 \mathrm{vol} \%$ water vapor, the propane concentration at the outlet was $630 \times 10^{-6} \mathrm{v} / \mathrm{v}$ as the oxygen content increased to $5 \%$ and $10 \%$. It can be seen from Figures 4 (a)-4(c) that the time required to reach reaction stability increased upon increasing the water concentration. The outlet propane concentration also increased as the water concentration increased. This may be due to the adsorption of water on the active sites of the catalyst surface, which hindered contact between propane and $\mathrm{O}_{2}$ molecules and active sites, thus inhibiting propane oxidation.

3.1.4. Effect of Hydrothermal Aging Treatment. Propane concentration as a function of time and conversion after hydrothermal aging of the CMC-1 catalyst is shown in Figure 5. As shown in Figure 5(a), the propane concentration rapidly stabilized at different reaction temperatures in the first 60 seconds, and then, it remained unchanged, indicating that the catalyst remained stable after hydrothermal aging treatment. As the temperature increased, the propane concentration at the outlet decreased, possibly due to the enhanced oxidation capacity. Figure 5(b) shows that 


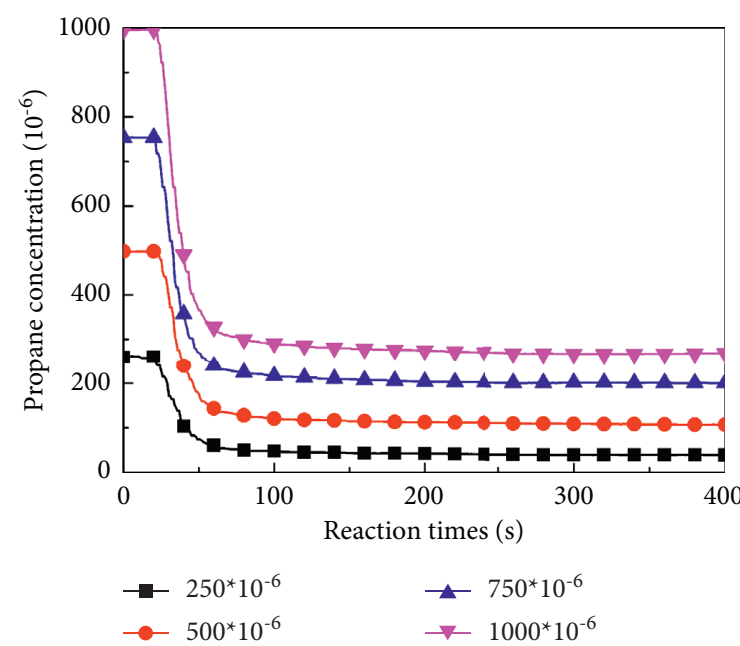

(a)

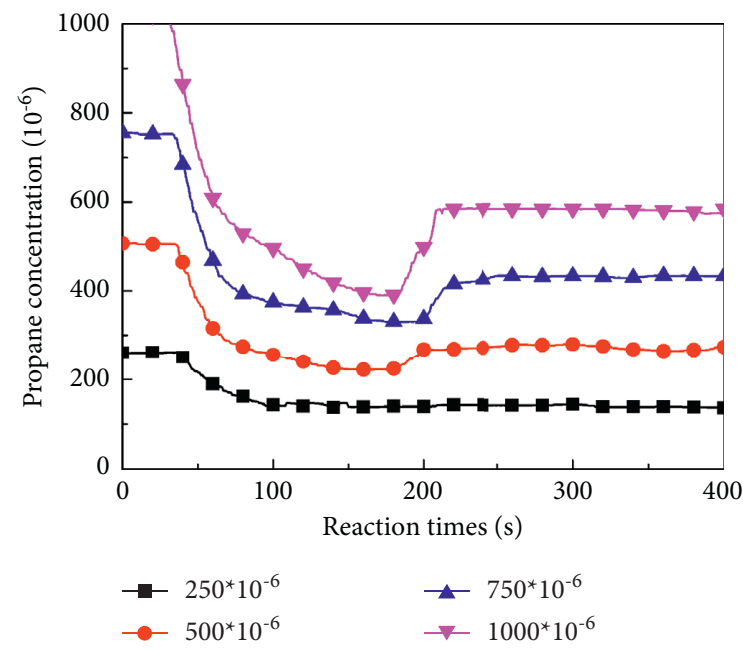

(c)

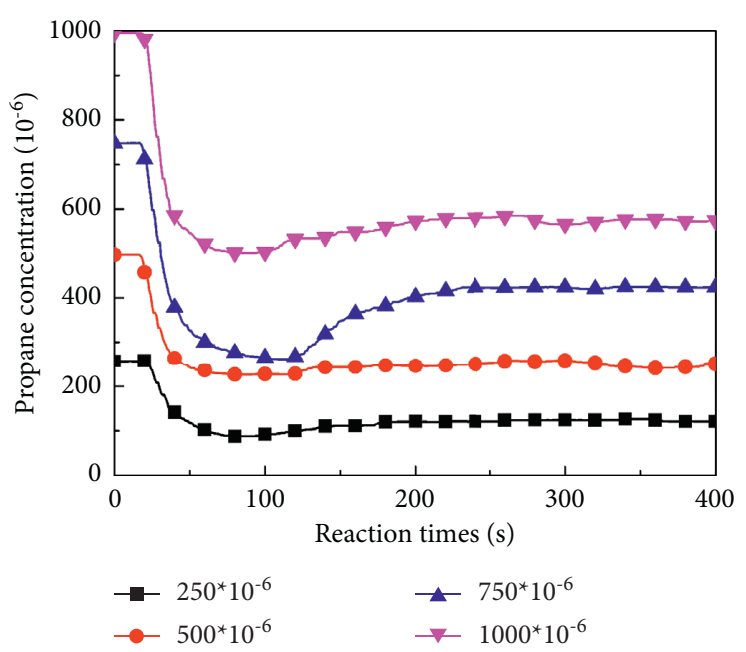

(b)

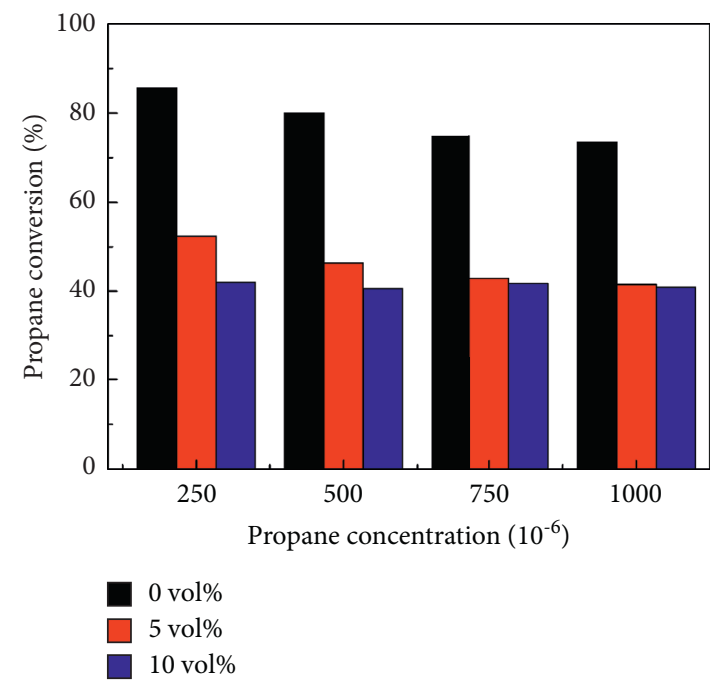

(d)

Figure 3: Propane concentration and propane conversion under different propane concentrations. (a) 0 vol\% water vapor. (b) 5 vol\% water vapor. (c) 10 vol\% water vapor. (d) Propane conversion.

the propane conversion reached $T_{10}$ above $250^{\circ} \mathrm{C}$ and $T_{80}$ was at $500^{\circ} \mathrm{C}$. It was found that after hydrothermal aging treatment, $T_{10}$ and $T_{80}$ increased by 60 and $80^{\circ} \mathrm{C}$, respectively, indicating that the activity of the catalyst decreased significantly after hydrothermal aging.

\subsection{Characterization of the Catalyst}

3.2.1. $\mathrm{O}_{2}-T P D$. The type and migration ability of oxygen species in the catalysts were studied through $\mathrm{O}_{2}$-TPD. Figure 6 shows the $\mathrm{O}_{2}$-TPD experiments of $\mathrm{Co}-\mathrm{Mn}$-Ce catalysts. The desorption sequence of surface oxygen species was generally as follows: $\mathrm{O}_{2}^{-}\left(\mathrm{O}_{\text {ads }}\right) \longrightarrow \mathrm{O}^{-}\left(\mathrm{O}_{\text {ads }}\right) \longrightarrow \mathrm{O}_{2-}$ $\left(\mathrm{O}_{\text {latt }}\right)$. Three broad peaks were observed at $182^{\circ} \mathrm{C}, 510^{\circ} \mathrm{C}$, and $700^{\circ} \mathrm{C}$. The peak at $182^{\circ} \mathrm{C}$ was assigned to desorption of $\mathrm{O}_{2}{ }^{-}$ and $\mathrm{O}^{-}$, both of which are the reactive oxygen species involved in oxidation. The second peak was associated with the desorption of $\mathrm{O}_{2-}[32,33]$. A strong peak was observed at $700^{\circ} \mathrm{C}$, which corresponded to the desorption of bulk lattice oxygen [34]. After aging, all desorption peaks shifted towards a higher temperature, which indicated that oxygen mobility was significantly affected, and the utilization of surface oxygen became difficult. The desorption peak of the fresh catalyst was much larger than that after hydrothermal aging, indicating the former had a higher concentration of oxygen species.

3.2.2. In Situ DRIFTs. The DRIFTs spectra used to explore the propane adsorption on the catalyst in a flow of $0.2 \%$ propane and $10 \% \mathrm{O}_{2}$ are shown in Figure 7. From Figures $7(\mathrm{a})$ and $7(\mathrm{~b})$, the spectra contained bands at 1422 and $1584 \mathrm{~cm}^{-1}$, which were associated with uncoordinated $\mathrm{CO}_{3}{ }^{2-}$ and $v_{\mathrm{as}}(\mathrm{COO})$, respectively [35]. These peaks suggested that surface oxygen species oxidized propane into intermediate species. The bands around 2300-2400 and $3730 \mathrm{~cm}^{-1}$ were attributed to gaseous $\mathrm{CO}_{2}$ and 

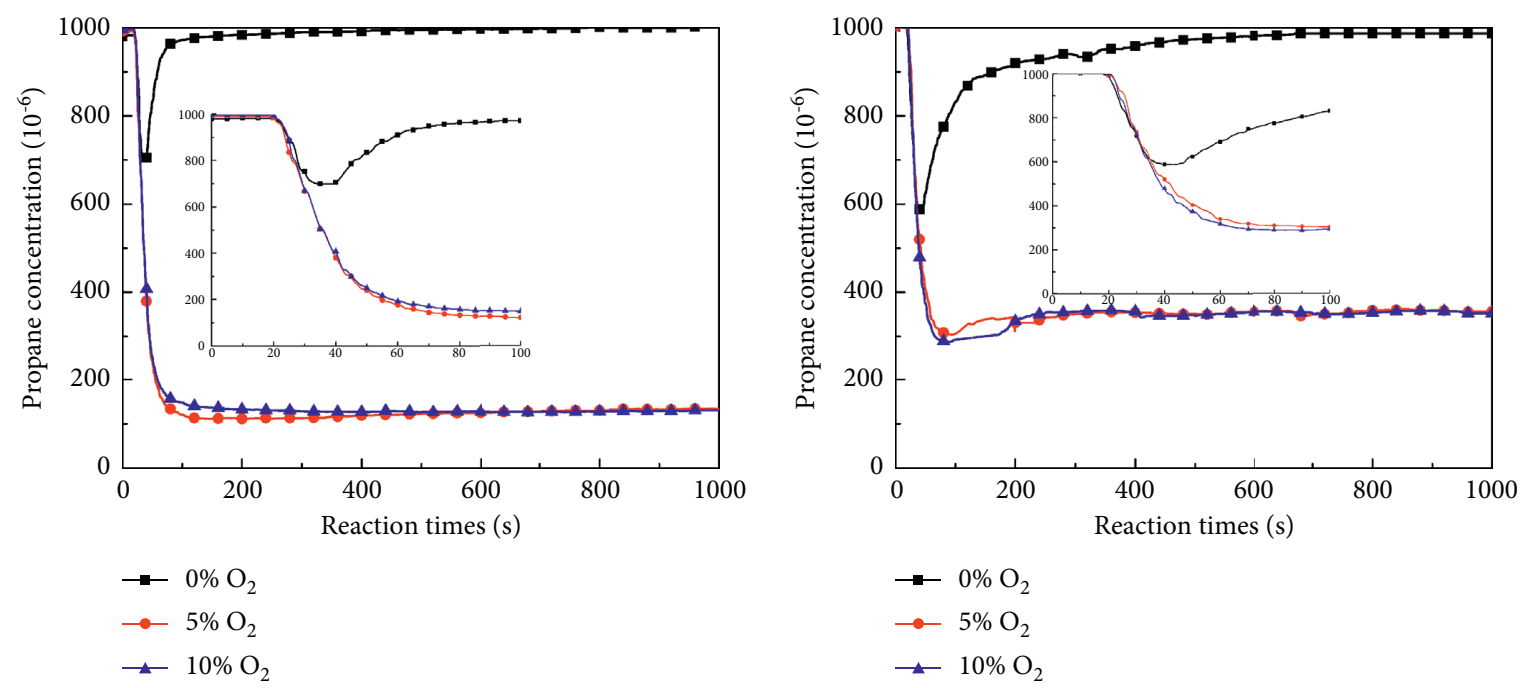

(a)

(b)

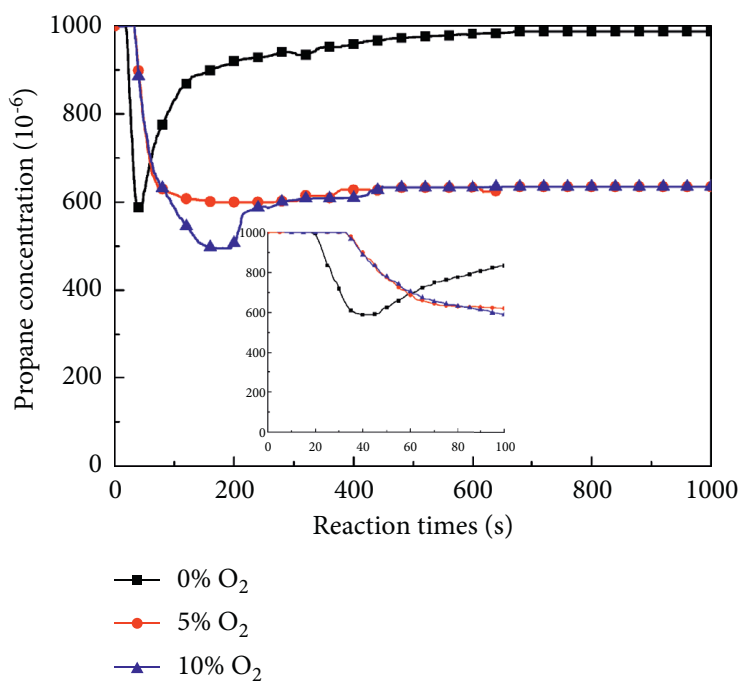

(c)

Figure 4: Propane concentration curve on CMC catalyst under different $\mathrm{O}_{2}$ concentrations. (a) 0 vol\% of water vapor. (b) 5 vol\% of water vapor. (c) 10 vol\% water vapor.

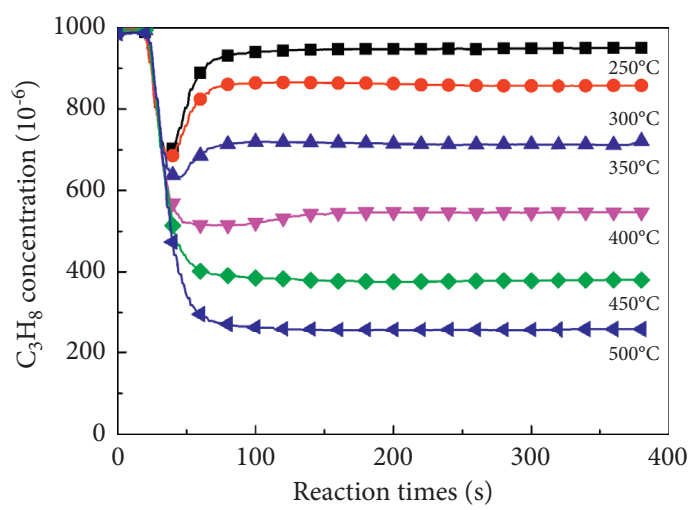

(a)

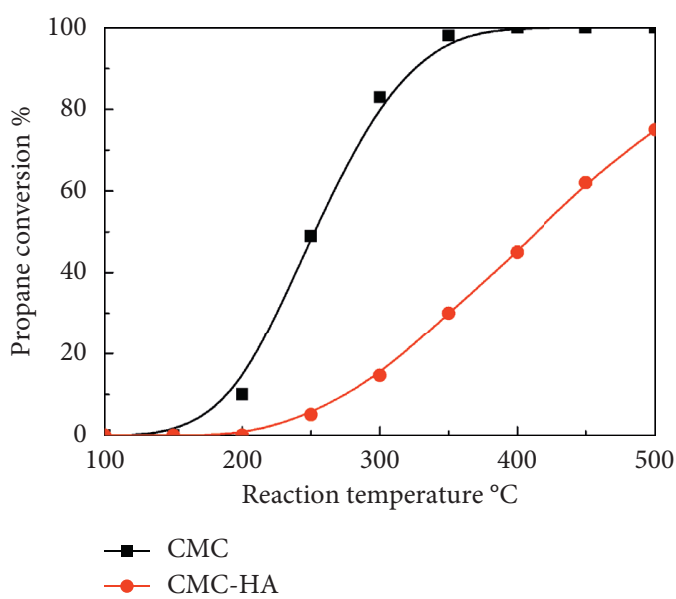

(b)

Figure 5: CMC-HA catalyst. (a) Propane concentration. (b) Propane conversion. 


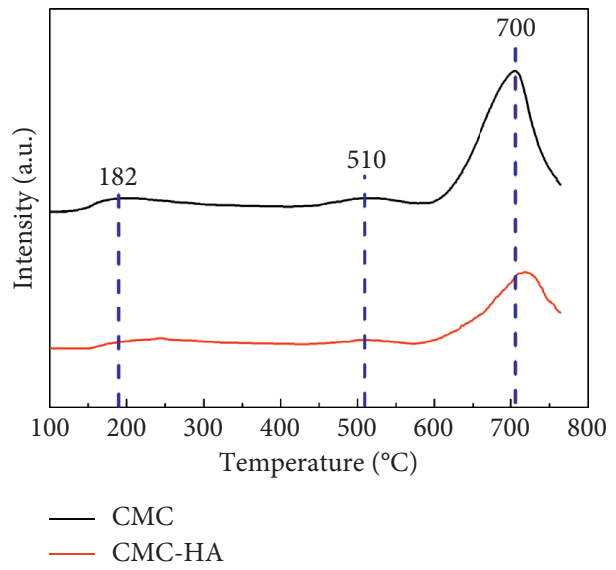

Figure 6: $\mathrm{O}_{2}^{-}$TPD curves of the CMC and CMC-HA catalysts.

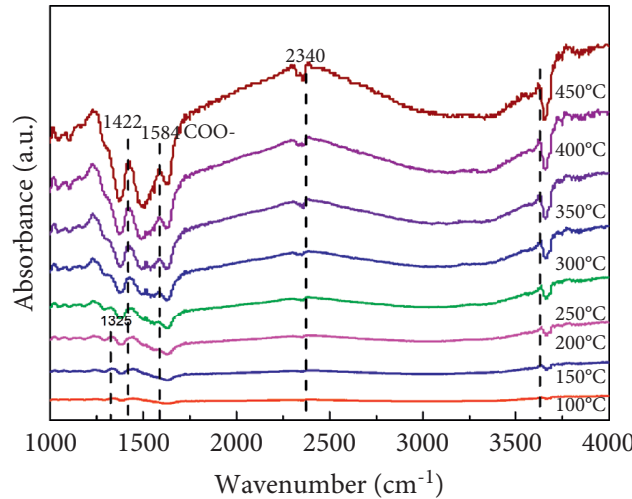

(a)

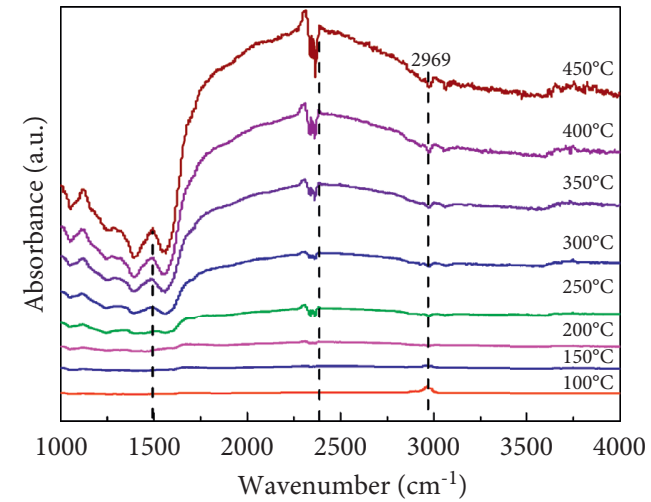

(b)

FIGURE 7: In situ DRIFTs spectra of propane adsorption on (a) CMC catalyst and (b) CMC-HA catalyst at $100-450^{\circ} \mathrm{C}$.

$v_{\text {as }}(\mathrm{OH})[36,37]$, suggesting the total oxidation of propane. The spectra of CMC-HA were similar to that of the CMC catalyst, indicating that the two catalysts followed the same reaction mechanism. CMC-HA catalysts exhibited similar behavior as shown in Figure 7(b), and the new bands attributed to $v_{\text {as }}(\mathrm{C}-\mathrm{H})$ at $2969 \mathrm{~cm}^{-1}$ and $\delta_{\text {as }}\left(\mathrm{CH}_{3}\right)$ at $1479 \mathrm{~cm}^{-1}$. The intensity of the peaks at 1422 and $1584 \mathrm{~cm}^{-1}$ was lower than the CMC catalyst, probably due to the much lower surface area after hydrothermal aging.

\section{Conclusion}

In this study, the effects of various reaction conditions were investigated over CMC catalysts by propane oxidation experiments. The catalytic oxidation experiments indicated that propane conversion was significantly different at $300^{\circ} \mathrm{C}$ under various water vapor concentrations. Propane conversion exceeded $95 \%$ at $400^{\circ} \mathrm{C}$. In addition, it also showed that the reaction times required to equilibrium extended upon increasing the water concentration. Under the same propane concentration, propane conversion decreased from $80 \%$ to $40 \%$ upon increasing the water concentration. Under the same water vapor concentration, propane conversion decreased by $10 \%$ upon increasing the propane concentration due to the presence of fewer active sites. When the concentration of $\mathrm{O}_{2}$ was $0 \%$, the propane concentration was $1000 \times 10^{-6} \mathrm{v} / \mathrm{v}$, which showed that $\mathrm{O}_{2}$ limited propane oxidation by the CMC-1 catalyst. After light hydrothermal aging, the oxidation activity of the catalyst decreased significantly. Notably, $\mathrm{O}_{2}$-TPD experiments demonstrated that the number of oxygen species $\left(\mathrm{O}_{2}^{-}\right.$and $\left.\mathrm{O}^{-}\right)$decreased after light hydrothermal aging. The stored species existed mainly as oxygenating intermediate over the CMC catalyst, while the stored species during propane oxidation existed as carbonate species over the CMC-HA catalyst in the DRIFTs experiments. It indicated that the oxidation path followed the same surface reaction mechanism after hydrothermal aging.

\section{Data Availability}

The data used to support the findings of this study are available from the corresponding author upon request.

\section{Conflicts of Interest}

The authors declare that they have no conflicts of interest. 


\section{Acknowledgments}

This work was supported by the National Natural Science Foundation of China (51906089), Postgraduate Research and Practice Innovation Program of Jiangsu Province (SJCX20_1422), National Engineering Laboratory Open Fund for Mobile Source Pollution Emission Control Technology (NELMS2018A18), and Zhenjiang Science and Technology Support Project (GY2020016).

\section{References}

[1] X. Zhu, S. Liu, Y. Cai et al., "Post-plasma catalytic removal of methanol over Mn-Ce catalysts in an atmospheric dielectric barrier discharge," Applied Catalysis B: Environmental, vol. 183, pp. 124-132, 2016.

[2] X. Zhu, S. Zhang, X. Yu et al., "Controllable synthesis of hierarchical $\mathrm{MnO} x / \mathrm{TiO} 2$ composite nanofibers for complete oxidation of low-concentration acetone," Journal of Hazardous Materials, vol. 337, pp. 105-114, 2017.

[3] L. Chen, Y. Liao, S. Xin, X. Song, G. Liu, and X. Ma, "Simultaneous removal of $\mathrm{NO}$ and volatile organic compounds (VOCs) by Ce/Mo doping-modified selective catalytic reduction (SCR) catalysts in denitrification zone of coal-fired flue gas," Fuel, vol. 262, Article ID 116485, 2020.

[4] K. Everaert and J. Baeyens, "Catalytic combustion of volatile organic compounds," Journal of Hazardous Materials, vol. 109, no. 1-3, pp. 113-139, 2004.

[5] Y. Guo, M. Wen, G. Li, and T. An, "Recent advances in VOC elimination by catalytic oxidation technology onto various nanoparticles catalysts: a critical review," Applied Catalysis B: Environmental, vol. 281, Article ID 119447, 2021.

[6] Q. Dai, S. Bai, J. Wang, M. Li, X. Wang, and G. Lu, "The effect of $\mathrm{TiO} 2$ doping on catalytic performances of $\mathrm{Ru} / \mathrm{CeO} 2$ catalysts during catalytic combustion of chlorobenzene," Applied Catalysis B: Environmental, vol. 142-143, pp. 222-233, 2013.

[7] S. Zuo, M. Ding, J. Tong, L. Feng, and C. Qi, "Study on the preparation and characterization of a titanium-pillared claysupported $\mathrm{CrCe}$ catalyst and its application to the degradation of a low concentration of chlorobenzene," Applied Clay Science, vol. 105-106, pp. 118-123, 2015.

[8] Q. Dai, S. Bai, X. Wang, and G. Lu, "Facile synthesis of HZSM5 with controlled crystal morphology and size as efficient catalysts for chlorinated hydrocarbons oxidation and xylene isomerization," Journal of Porous Materials, vol. 21, no. 6, pp. 1041-1049, 2014.

[9] S. Behar, N.-A. Gómez-Mendoza, M.-Á. Gómez-García, D. Świerczyński, F. Quignard, and N. Tanchoux, "Study and modelling of kinetics of the oxidation of VOC catalyzed by nanosized $\mathrm{Cu}-\mathrm{Mn}$ spinels prepared via an alginate route," Applied Catalysis A: General, vol. 504, pp. 203-210, 2015.

[10] X. Wang, W. Zhao, X. Wu et al., "Total oxidation of benzene over ACo $2 \mathrm{O} 4(\mathrm{~A}=\mathrm{Cu}, \mathrm{Ni}$ and $\mathrm{Mn})$ catalysts: in situ DRIFTS account for understanding the reaction mechanism," Applied Surface Science, vol. 426, pp. 1198-1205, 2017.

[11] Y. Ma, Y. Li, M. Mao, J. Hou, M. Zeng, and X. Zhao, "Synergetic effect between photocatalysis on $\mathrm{TiO} 2$ and solar light-driven thermocatalysis on $\mathrm{MnOx}$ for benzene purification on $\mathrm{MnOx} / \mathrm{TiO} 2$ nanocomposites," Journal of Materials Chemistry, vol. 3, no. 10, pp. 5509-5516, 2015.

[12] C. He, Y. Yu, Q. Shen, J. Chen, and N. Qiao, "Catalytic behavior and synergistic effect of nanostructured mesoporous
CuO-MnOx-CeO2 catalysts for chlorobenzene destruction," Applied Surface Science, vol. 297, pp. 59-69, 2014.

[13] J. Zhu and Q. Gao, "Mesoporous MCo2O4 ( $\mathrm{M}=\mathrm{Cu}, \mathrm{Mn}$ and $\mathrm{Ni}$ ) spinels: structural replication, characterization and catalytic application in CO oxidation," Microporous and Mesoporous Materials, vol. 124, no. 1-3, pp. 144-152, 2009.

[14] H. Zhao, H. Wang, and Z. Qu, "Synergistic effects in Mn-Co mixed oxide supported on cordierite honeycomb for catalytic deep oxidation of VOCs," Journal of Environmental Sciences, vol. 112, pp. 231-243, 2022.

[15] W. Tang, X. Wu, S. Li, W. Li, and Y. Chen, "Porous Mn-Co mixed oxide nanorod as a novel catalyst with enhanced catalytic activity for removal of VOCs," Catalysis Communications, vol. 56, pp. 134-138, 2014.

[16] M. H. Castaño, R. Molina, and S. Moreno, "Cooperative effect of the Co-Mn mixed oxides for the catalytic oxidation of VOCs: influence of the synthesis method," Applied Catalysis A: General, vol. 492, pp. 48-59, 2015.

[17] W. Tang, X. Wu, G. Liu et al., "Preparation of hierarchical layer-stacking $\mathrm{Mn}$-Ce composite oxide for catalytic total oxidation of VOCs," Journal of Rare Earths, vol. 33, no. 1, pp. 62-69, 2015.

[18] L. Geng, B. Chen, J. Yang et al., "Synergistic effect between Mn and Ce for active and stable catalytic wet air oxidation of phenol over MnCeOx," Applied Catalysis A: General, vol. 604, pp. 117774-117783, 2020.

[19] Z.-Y. Tian, P. H. Tchoua Ngamou, V. Vannier, K. KohseHöinghaus, and N. Bahlawane, "Catalytic oxidation of VOCs over mixed Co-Mn oxides," Applied Catalysis B: Environmental, vol. 117-118, pp. 125-134, 2012.

[20] S. Feng, J. Liu, and B. Gao, "Synergistic mechanism of Cu-MnCe oxides in mesoporous ceramic base catalyst for VOCs microwave catalytic combustion," Chemical Engineering Journal, vol. 429, pp. 132302-132313, 2022.

[21] L. Deng, Y. Ding, B. Duan et al., "Catalytic deep combustion characteristics of benzene over cobalt doped Mn-Ce solid solution catalysts at lower temperatures," Molecular Catalysis, vol. 446, pp. 72-80, 2018.

[22] D. M. Gómez, V. V. Galvita, J. M. Gatica, H. Vidal, and G. B. Marin, "TAP study of toluene total oxidation over a $\mathrm{Co} 3 \mathrm{O} 4 / \mathrm{La}-\mathrm{CeO} 2$ catalyst with an application as a washcoat of cordierite honeycomb monoliths," Royal Society of Chemistry, vol. 16, no. 23, pp. 11447-11455, 2014.

[23] J. Kan, L. Deng, B. Li et al., "Performance of co-doped Mn-Ce catalysts supported on cordierite for low concentration chlorobenzene oxidation," Applied Catalysis A: General, vol. 530, pp. 21-29, 2017.

[24] C. Yang, G. Miao, Y. Pi et al., "Abatement of various types of VOCs by adsorption/catalytic oxidation: a review," Chemical Engineering Journal, vol. 370, pp. 1128-1153, 2019.

[25] P. Wang, C. Cui, K. Li, J. Yi, and L. Lei, "The effect of Mn content on catalytic activity of the Co-Mn-Ce catalysts for propane oxidation: importance of lattice defect and surface active species," Catalysis Letters, vol. 150, no. 5, pp. 1505-1514, 2019.

[26] M. Ghafari and J. D. Atkinson, “One-step hyper-cross-linking of porous styrenic polymers using dichloroalkane crosslinkers to maintain hydrophobicity," Polymer, vol. 116, pp. 278-286, 2017.

[27] Q. Dai, X. Wang, and G. Lu, "Low-temperature catalytic combustion of trichloroethylene over cerium oxide and catalyst deactivation," Applied Catalysis B: Environmental, vol. 81, no. 3-4, pp. 192-202, 2008. 
[28] C. H. Bartholomew, "Mechanisms of catalyst deactivation," Applied Catalysis A: General, vol. 212, no. 1-2, pp. 17-60, 2001.

[29] R. López-Fonseca, A. Aranzabal, and P. Steltenpohl, "Performance of zeolites and product selectivity in the gas-phase oxidation of 1,2-dichloroethane," Catalysis Today, vol. 62, pp. 367-377, 2000.

[30] W. B. Li, M. Zhuang, T. C. Xiao, and M. L. H. Green, "MCM41 supported $\mathrm{Cu}-\mathrm{Mn}$ catalysts for catalytic oxidation of toluene at low temperatures," The Journal of Physical Chemistry B, vol. 110, no. 43, pp. 21568-21571, 2006.

[31] J. Bae, B.-S. Kim, H. Jeong, and H. Lee, "Mn-doped $\mathrm{CuO}$ $\mathrm{Co} 3 \mathrm{O} 4 \mathrm{CeO} 2$ catalyst with enhanced activity and durability for hydrocarbon oxidation," Molecular Catalysis, vol. 467, pp. 9-15, 2019.

[32] L. Xue, C. Zhang, H. He, and Y. Teraoka, "Catalytic decomposition of $\mathrm{N} 2 \mathrm{O}$ over $\mathrm{CeO} 2$ promoted $\mathrm{Co} 3 \mathrm{O} 4$ spinel catalyst," Applied Catalysis B: Environmental, vol. 75, no. 3-4, pp. 167-174, 2007.

[33] S. Xie, Y. Liu, J. Deng et al., "Three-dimensionally ordered macroporous CeO2-supported Pd@Co nanoparticles: highly active catalysts for methane oxidation," Journal of Catalysis, vol. 342, pp. 17-26, 2016.

[34] G. Yang, Y. Li, and Y. Men, "Synergistic catalysis effect of Mnpromoted $\mathrm{BaAl} 2 \mathrm{O} 4$ catalysts on catalytic performance for soot combustion," Catalysis Communications, vol. 69, pp. 202-206, 2015.

[35] X. Li, X. Li, X. Zeng, and T. Zhu, "Correlation between the physicochemical properties and catalytic performances of micro/mesoporous $\mathrm{CoCeO}$ mixed oxides for propane combustion," Applied Catalysis A: General, vol. 572, pp. 61-70, 2019.

[36] S. Mo, Q. Zhang, Y. Sun et al., "Gaseous CO and toluene cooxidation over monolithic core-shell Co3O4-based heterostructured catalysts," Journal of Materials Chemistry, vol. 7, no. 27, pp. 16197-16210, 2019.

[37] M. Guo, K. Li, H. Zhang et al., "Promotional removal of oxygenated VOC over manganese-based multi oxides from spent lithium-ions manganate batteries: modification with $\mathrm{Fe}$, $\mathrm{Bi}$ and Ce dopants," The Science of the Total Environment, vol. 740, Article ID 139951, 2020. 